\title{
POR UMA GEOCIÊNCIA AMBIENTAL
}

\author{
C.C.Roncaratti ${ }^{1}$ \\ N.L.S.Ferreira ${ }^{1}$ \\ F.Levi²
}

$\mathrm{Na}$ interface existente entre o ambiente geoquímico e as ciências humanas, o primeiro tem sido estudado tradicionalmente enfatizando aspectos econômicos como a prospecção e exploração dos mais diversos bens minerais. Uma visão transdisciplinar desta interface está possibilitando a abertura de novas fronteiras do conhecimento.

Há diferentes papéis exercidos pelos constituintes na relação organismo-ambiente: adaptação coevolutiva, absorção ocasional com efeitos de toxidez, de nutrição ou indiferença e situações de interação complexas. As anomalias geoquímicas podem existir naturalmente ou como decorrência de uma atividade antrópica. Assim a superfície de nosso planeta pode ser vista como um mosaico de fatores que afetam a qualidade de vida em diversos sentidos. Há fortes indícios de que teores de $\mathrm{Pb}, \mathrm{Hg}, \mathrm{Cd}, \mathrm{Cr}$ e $\mathrm{Ni}$ exercem efeitos sutis e a longo prazo.

Os mapeamentos epidemiológico, fisiográfico e geoquímico indicam, ocasionalmente, correlações marcantes e inesperadas. Isto fez com que surgissem novas especialidades nas geociências, relacionando saúde, ciclo geoquímico, evolução, qualidade de vida e hábitos culturais.

Acreditar que estamos vivendo um progressivo esclarecimento sobre as questões ambientais é portanto uma ilusão. Nestas questões o que ocorre de fato é uma tentativa inútil de ignorar a complexidade, uma oscilação entre o determinismo herdado da ciência clássica e um desespero que leva a fanatismos, misticismos, esoterismos ou apatia e desilusão. Respostas

\footnotetext{
1Pós-graduação, Departamento de Geologia, Geral, Instituto de Geociências, USP.

2Departamento de Geologia Geral, Instituto de Geociências, USP.
} 
insatisfatórias ou evasivas são colocadas e falsamente comprendidas a partir de contextos puramente técnicos, como se estivéssemos perante uma fenomenologia aleatória frente a qual não se pudesse melhorar nosso conhecimento, tanto sobre os principais mecanismos de interação global como sobre seus reflexos nas particularidades paisagísticas e culturais de diversos locais do sistema Terra.

A geologia nos ensina que nosso planeta e tudo o que parecia representar um quadro fixo de nossa existência, é fruto de longas histórias marcadas por criações e destruições, não umas em oposição às outras, ordenando e desordenando, mas onde a ordem e a desordem se situam em indissociável complementação como a do metamorfismo e magmatismo, da especiação e extinção, do nascimento e da morte, da síntese e posterior decomposição.

Ao longo do tempo geológico, o Registro assinala que o turbilhonamento material bem como o fluxo de nutrientes e dejetos que sustentam a vida, além de variar e flutuar, tem se acelerado também. Analogamente, a industrialização segue uma história similar, de variação, flutuação e aceleração.

Consequentemente, buscamos um entendimento tentando nos voltar para a história química da Terra, tentando entender o presente em termos dos períodos pregressos, através de estudos sobre a simulação matemática de modelos globais. Entendemos que assim nosso conhecimento, de laboratório e regional, possa ser estendido para escalas maiores.

Do ponto de vista geoquímico, podemos considerar a origem das geoesferas, inicialmente, através de mecanismos de diferenciação de um material de composição meteoritica, caracterizando-se por envoltórios sucessivos que de certa forma dominam o planeta - manto, crosta, biosfera e a mais recente antroposfera. Em sua evolução, estas geoesferas geram subprodutos de diferentes densidades e estados de agregação, dando origem a geoesferas "subprodutos": a atmosfera, hidrosfera e os sedimentos.

O quadro geral da migração dos elementos na parte exterior do planeta nos fornece o conceito de natureza estrutural de ciclo geoquímico, envolvendo, de uma maneira complexa, o ciclo das rochas, o ciclo da água e os ciclos tectônicos, todos referidos, em última instância, ao material que forneceu a matéria prima inicial.

Modelos globais envolvem considerações sobre fenômenos reais, simplificados para grandes escalas, que constituem, primariamente, instrumentos analíticos, elaborados para direcionar as transferências materiais entre a superfície, a atmosfera e os oceanos.

Porém, em geral, a análise de amostras de materiais ambientais, jamais poderá seguir um programa planetário de profilaxia, simplesmente porque a velocidade de produção de dados integrados, é sempre superada pela velocidade de produção de novos materiais, cujas variedades e 
atividades crescentes, e cujos efeitos, previsíveis e imprevisíveis, fatalmente virão.

$\mathrm{O}$ assunto merece muita aplicação, esforço e reflexão. Não é uma visão de mundo que queremos partilhar, mas sim uma visão da ciência. Não há dúvida que a incapacidade de uma civilização em preservar o meio ambiente do qual depende para existir e sustentar-se pode ser tanto um sinal de extinção como um alerta para a sobrevivência. 